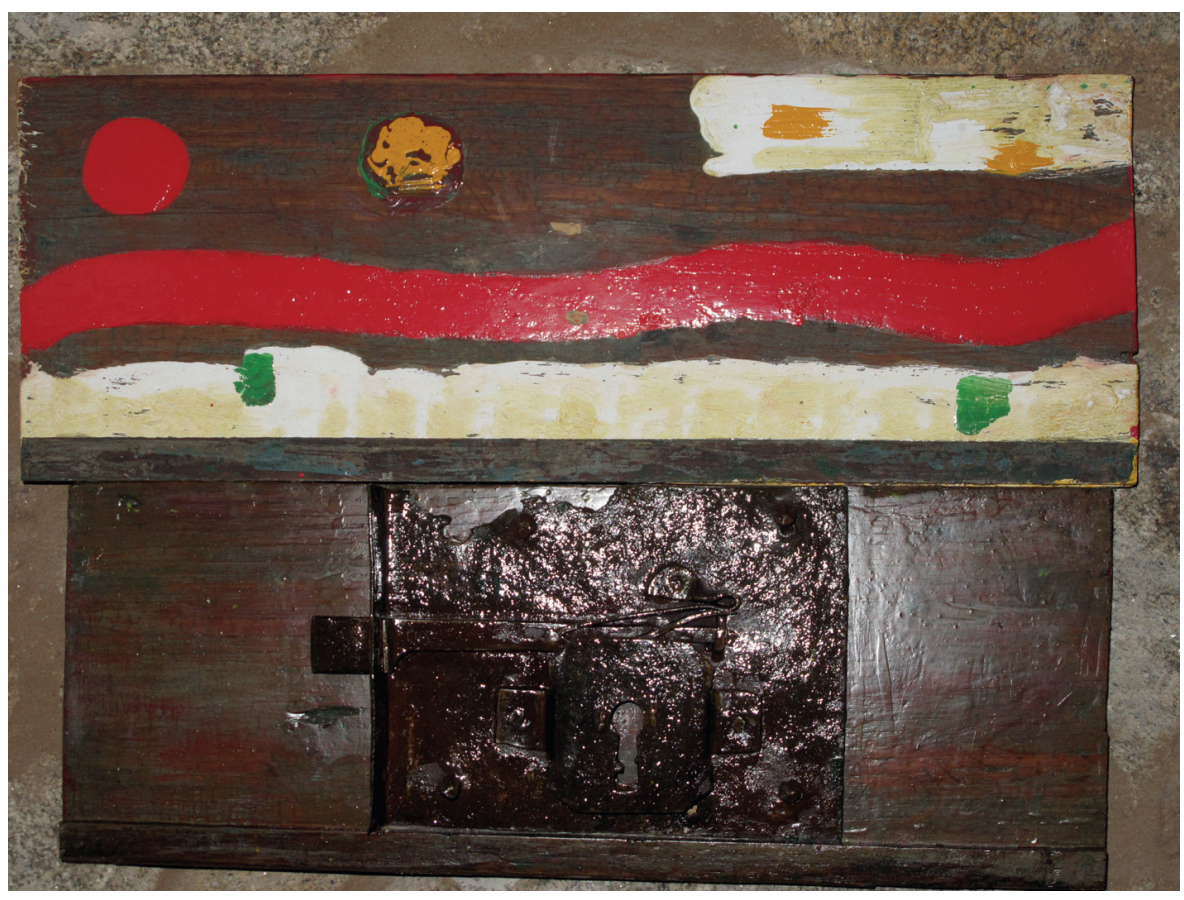


ILUSTRACión: Apocalipse

AUTOR: A. T. 


\title{
Teatro xuvenil e memoria histórica: Con Franco nun armario de Bernardino Graña
}

\author{
Laura Piñeiro Pais \\ [Recibido, 26 setembro 2016; aceptado, 15 decembro 2016] \\ http://dx.doi.org/10.15304/bgl.51.3444
}

RESUMO A consecuencia do golpe militar de 1936, o teatro galego foi practicamente inexistente en Galicia ata a fundación da editorial Galaxia a comezos dos anos cincuenta. É precisamente en Galaxia onde Bernardino Graña inicia a súa angueira teatral coa publicación de Vinte mil pesos crime en 1962. O seu labor no eido da dramaturxia non cesará ata 2010, ano en que publica a farsa para nenos Larpancia saborosa do lobo e da raposa, ata o momento, a última peza teatral publicada polo autor. Neste artigo faremos un percorrido pola dramaturxia de Bernardino Graña centrándonos na análise da peza Con franco nun armario, publicada en 2009 por A Nosa Terra, da que analizaremos os temas principais e os motivos temáticos da violencia e da crítica social e histórica presentes nesas páxinas.

PALABRAS CHAVE: Teatro galego, editorial Galaxia, violencia, crítica social e histórica.

ABSTRACT As a result of the military coup in 1936, the Galician theatre was practically non-existent until the foundation of the publishing house Galaxia at the beginning of the sixties. It is precisely in Galaxia where Bernardino Graña initiates his theatrical job with the publication of Vinte mil pesos crime in 1962. His activity in the field of dramaturgy will not cease until 2010, when he publishes the farce for children Larpancia saborosa do lobo e da raposa, the last dramatic play published by the author so far. In this article, we will discuss the dramatic activity of Bernardino Graña focusing on the work Con franco nun armario, published in 2009 by A Nosa Terra, where we will analyze the main themes and the thematic motifs of violence and of social and historical criticism present in these pages.

KEYWORDS: Galician theatre, publisher Galaxia, violence, social and historical criticism. 


\section{Introdución}

En 1931, o polígrafo coruñés Leandro Carré Alvarellos publica no Boletín da Real Academia Galega un compendio sobre dramaturxia galega —que abrangue desde século XVIII ata o ano 1929- que titulou "Apontamentos para a historia do teatro galego". Nese artigo, o autor analiza a situación da dramaturxia en Galicia e explica como o desenvolvemento da prosa fai concibir certas esperanzas de prosperidade para a lingua. A diferenza do terreo narrativo, Carré Alvarellos (1931: 213) explica que aínda que a modalidade dramática foi unha das máis "levadas e traídas" en Galicia, había quen á altura de 1930 afirmaba que non existía realmente teatro en lingua galega.

As esperanzas depositadas na dramaturxia anterior á Guerra Civil, que legou obras como A patria do labrego, de Antón Villar Ponte; A man de Santiña, de Ramón Cabanillas; A fiestra valdeira, de Rafael Dieste ou $A$ lagarada, de Ramón Otero Pedrayo, entre outras, disípanse co golpe militar de 1936. A publicación de teatro galego durante a posguerra, e por extensión de gran parte da literatura de noso, foi practicamente inexistente en Galicia ${ }^{1}$ ata a fundación da editorial Galaxia e da revista Grial, esta última o máis importante vehículo para a literatura dramática en galego (Riobó 1999: 13). Na colección Illa Nova de Galaxia viron a luz as seguintes pezas teatrais: Vieiro choído (1957), de Xosé Luís Franco Grande, e Vinte mil pesos crime (1962), de Bernardino Graña. Entre as obras de X. L. Franco Grande e Bernardino Graña, sae do prelo en 1958, tamén en Galaxia, O incerto señor Don Hamlet Príncipe de Dinamarca, de Álvaro Cunqueiro, considerada un punto de partida para a renovación da dramaturxia galega posterior. En palabras de Héitor Mera (2005: 20), a dramaturxia da "Promoción Grial" xustaponse á do grupo Nós e ao da diáspora e conta cos seguintes membros: Jenaro Marinhas del Valle, Ricardo Carballo Calero, Álvaro Cunqueiro, Dora e Pura Vázquez, os máis vellos; e Ramón González-Alegre Bálgoma, Daniel Cortezón, Manuel María, Xohana Torres e Bernardino Graña, os máis novos, e teñen en común os seguintes trazos: a reconstrución crítica da realidade; a utilización do texto

\footnotetext{
Porén, non podemos pasar por alto a actividade teatral galega en América durante a primeira etapa da ditadura. En palabras de Pedro Pablo Riobó (1999: 14): "Bos Aires é o centro do teatro galego da época, continuando así unha tradición que se iniciara co século. As editoriais galegas bonaerenses contribuirán decisivamente á recuperación teatral do noso país ao abriren unha porta de saída para os textos que se producían tanto na emigración como na Galiza. As actividades dramáticas dalgúns dos autores máis significados (Castelao, Blanco-Amor, Seoane, Varela Buxán...) tiveron alí unha concreción que no país era imposíbel".
} 
dramático como instrumento de intervención, de loita —mais tendo en conta a calidade do produto-; a preocupación pola situación socio-política de Galicia e pola intervención a través da literatura dramática e a non investigación nin innovación da técnica teatral. A partir de 1962, ano de publicación de Vinte mil pesos crime, a angueira teatral de Bernardino Graña non cesará ata 2010 con Larpancia saborosa do lobo e da raposa, V Premio Estornela de Teatro para Nenos 2008 e, ata o momento, a última obra dramática publicada polo autor.

Neste artigo faremos un percorrido pola dramaturxia de Bernardino Graña centrándonos na análise da peza Con franco nun armario, publicada en 2009 por A Nosa Terra, da que analizaremos os temas principais e os motivos temáticos da violencia e da crítica social e histórica.

\section{A teima teatral}

Bernardino Graña (Cangas de Morrazo, 1932) comeza a súa angueira teatral en 1962 coa publicación de Vinte mil pesos crime na colección Illa Nova da editorial Galaxia. A obra está considerada un "drama de acción” (Fontoira Surís 1973: 365), porque os cinco cadros nos que se divide xiran arredor dun acontecemento que se descobre ao final. Segundo Carballo Calero (en Fontoira Surís 1973: 365), o texto ten como punto de partida a xornada IV da novela $\mathrm{V}$ do Decamerón de Boccacio, que trata dos amores infelices e que coincide, case na súa totalidade ${ }^{2}$, coa proposta do dramaturgo cangués. Vinte mil pesos crime conta a historia dos amores de Nieves e Venancio e as intrigas dos dous irmáns dela, Lisardo e Xaime, que matan a Venancio para que non chegue a casar coa súa irmá. Cinco meses despois desa morte, os irmáns sospeitan que Nieves está esperando un fillo do defunto, pero finalmente a trama desvela que o pai do fillo de Nieves é Paulino e non Venancio. O outro misterio preséntase tras a marcha de Xaime ao mar, cando a Lisardo lle rouban os seus aforros: vinte mil pesos. O final descobre que a Carrexa, a criada, é a culpable do furto dos cartos, así como tamén de que Paulino conseguise entrar na casa familiar e deitarse con Nieves.

2 Héitor Mera (2005: 74) enumera detalladamente na súa edición as diferenzas entre o texto de Boccacio e o de Bernardino Graña en canto a trama, personaxes e outros elementos literarios. Porén, nas "Conversas" que mantén co propio autor, este afirma que o Decamerón supuxo unicamente un punto de partida para ter unha trama argumental, como podería selo tamén unha frase oída na rúa. 
Un ano despois da publicación de Vinte mil pesos crime fúndase na Coruña a Agrupación Cultural O Facho, unha iniciativa dun grupo de defensores da lingua, da cultura e da política galegas durante a ditadura. O colectivo organizou cursos de galego e certames literarios de gran repercusión. En 1973, Bernardino Graña recibe mención honorífica no I Concurso de Teatro Infantil O Facho coa peza Sinfarainín contra don Perfeuto, representada nos institutos de Padrón e Vilagarcía e publicada en 1975 no número 48 da revista Grial. A peza, dirixida ao lectorado infantil, mestura fantasía e realidade por medio do diálogo entre animais e humanos, neste caso, Pacucho Caichovento, que sufre insomnio por mor dun reloxo impertinente chamado don Perfeuto.

Nese mesmo ano — ata 1980-a Asociación Cultural Abrente de Ribadavia convoca a Mostra de Teatro Abrente, un certame de vital importancia para a recuperación do teatro galego que congregou a un grupo de dramaturgos que posteriormente a crítica denominaría Xeración Abrente ${ }^{3}$. Nas conversas con Rafael Fernández e Héitor Mera (2005: 61), Bernardino Graña repasa a súa experiencia teatral, vinculada a Ribadavia e a Abrente:

O teatro, para min, foi unha experiencia moi bonita, que ademais, coincidiu que se deu como un renacer do teatro galego en Ribadavia, e Ribadavia, para min, é unha vila entrañable [...] Ribadavia vai unido a moitas cousas da miña vida, da miña infancia e do comenzo da miña xuventude, e tamén vai unida ao teatro. Eu soñaba con que se representara algún día ou en Ribadavia ou nalgún sitio unha obra miña de teatro.

Desafortunadamente, o desexo do autor por representar en Ribadavia non se veu cumprido, mais na VII Mostra de Teatro Abrente celebrada en 1979 obtén o galardón coa peza Os burros que comen ouro (nunca cabalos serán), que non sería publicada ata 1992. A obra comeza cun introito do autor no que reflexiona sobre a realidade do teatro galego de finais dos setenta, a necesidade de crear textos cargados de ironía crítica e humor e sobre algunhas cuestións relacionadas directamente coa obra á que antecede, como a lingua, os personaxes, o público ao que vai dirixida etc. $\mathrm{O}$ texto pertence á cuarta titiritada da serie "sinfarainadas", xa que no elenco de personaxes aparece o sinfarainín, o protagonista da peza Sinfarainín contra don Perfeuto. A obra está dividida en

3 Nela inclúense nomes como os de Camilo Valdeorras, Roberto Vidal Bolaño, Manuel Lourenzo, Euloxio Rodríguez Ruibal ou Xosé Agrelo Hermo. 
dous lances e un breve intermedio onde se relata, por unha banda, o conflito dunha parella de labregos, Carmela e Sacaterra, que se debaten entre quedar cuns cartos que perdeu o cacique da aldea ou devolvelos e continuar coa súa vida humilde e, por outra, unha sucesión de preitos entre Sacaterra e outros personaxes como o Serrano e a súa muller, o Cacicón etc., moderados por un Xuíz e un Escribano, que se encargan de resolver finalmente os diferentes litixios. Nesta obra, tal e como observabamos con anterioridade no Sinfarainin, animais — entre eles a Pega Rabilonga, os burros augador e labrego ou o cínife Sinfarainín-, humanos, obxectos e fantasía mestúranse no segundo lance para desfrutar da entroidada e da vitoria dos labregos sobre o Cacicón. É interesante desde o punto de vista lingüístico a utilización do verso rimado —octosílabo fundamentalmente- e a introdución de refráns e cancións populares nun discurso teatral que, desde as palabras limiares do autor, sabemos que está vinculado á tradición popular e ao folclore galego.

Case unha década despois da publicación da peza Os burros que comen ouro, a Fundación Neira Vilas convoca no ano 2000 os Premios Arume e Estornela, o primeiro de poesía e o segundo de dramaturxia, dirixidos ambos os dous ao público infantil co obxectivo de "proporcionarlle á nenez obras que poida representar” (Agrelo Costas en Roig 2015: 294). O galardón da quinta edición do Premio Estornela de Teatro para nenos foi para a peza Larpancia saborosa do Lobo e a Raposa. Farsa de monifates nun lance, asinada por Bernardino Graña e publicada en Edicións Embora en 2010. A obra, construída nun único lance, conta a historia dunha parella de labregos e dos seus animais - unha vaca, un cocho, unha raposa e un lobo- que argallan o xeito de conseguir o sustento que os seus amos lles negan. Nun primeiro lugar é o labrego quen modera o encontro entre os animais e posteriormente entra en escena $o$ sinfarainín, que se encarga de planear — consumado polo lobo e a raposa- 0 roubo da comida a uns excursionistas. A farsa desenvólvese nun ambiente vilego, en terras do Morrazo, un espazo da historia que o lector coñece a partir dos datos que proporcionan os personaxes sobre a toponimia do lugar: o mar de Marín, Ons, Aldán... lugares que se recrean de xeito reiterado en toda a literatura do autor. En canto á estrutura lingüística destacamos novamente a utilización de metros populares, fundamentalmente de arte menor —octosílabos, pentasílabos, hexasílabos-e a presenza de ditos populares e cancións, que conectan novamente a dramaturxia de Bernardino Graña coa oralidade e coa tradición popular galega. 


\section{Violencia e crítica da historia en Con Franco nun armario}

Bernardino Graña publica en 2009 (Vigo, A Nosa Terra) a que sería a súa cuarta obra teatral, Con Franco nun armario, ilustrada por Anxo Fariña. O texto está dividido en dous lances inaugurados por un prólogo de Héitor Mera. Nese limiar, "Verbas sobre un teimudo", o crítico repasa a angueira teatral do autor e achega o lector ao que será a obra en cuestión, Con Franco nun armario, versión definitiva dunha peza que ten como antecedentes "Unha vella en auto-stop"e "Nun caseto que vai ser un banco". Así mesmo, fai fincapé no compoñente humorístico e na crítica social da obra. Continuando o camiño iniciado en décadas anteriores, Bernardino Graña volve a crear teatro para a mocidade coa fin de formar o lector do futuro e aproximalo á historia recente do país. A acción desenvólvese nunha pequena cidade ou vila mariñeira pouco despois da morte de Franco, a finais de 1975. Os personaxes, unha familia composta por unha vella; os seus dous fillos, un policía e o outro deficiente psíquico; un fillastro, empregado bancario; unha neta e unha nora, filla e muller do banqueiro, agardan polo camión de mudanzas para trasladar todos os seus obxectos persoais da casa familiar a un piso nun lugar máis moderno e urbanizado.

O inicio do primeiro lance preséntanos, non exento de carga de ironía e humor, a tres dos personaxes, Estreliña, Román e Castora. Da primeira, a filla, destaca a súa fachenda, as súas "entradas e saídas" e o interese polas noticias da radio — que versan sobre a morte do ditador-; de Román, o pai, a súa presunción e de Castora, nai e muller, a fatiga polo traballo. Pola súa banda, a vella laméntase da falta de estima e consideración por parte da familia. Castora e Román, a medida que van tirando os recordos da vella ao lixo, fúndense en gabanzas e novos desexos para o piso novo. Román pretende ascender de posto na empresa e na escala social e esa situación xunto coas ansias por abandonar rapidamente a casa familiar provoca continuas disputas entre el e a súa muller. Mentres os seus pais deciden que facer durante a mudanza con Avalino, o fillo deficiente da vella, Estreliña comenta as noticias sobre a morte de Franco. O humor e a sátira social intensifícanse ao final do primeiro lance cando aparece Avalino cunha cabeza de porco para lle regalar ao director do banco. Os personaxes fan referencia ao trastorno que viven tras a morte de Franco. A chegada de Pepe, retratado como un gabancioso e mullereiro garda municipal, pecha o primeiro lance. 
A segunda parte da obra comeza con Avalino dentro do armario. Castora e Román engánano dicíndolle que é noite para que non saia durante a mudanza. A vella, que observa a crueldade coa que tratan o seu fillo, dóese da situación e increpa a Román e Castora, que porfían en ter pechado a Avalino no armario. Neste segundo lance, a acción dramática cambia o seu cariz humorístico no momento en que a vella morre dun ataque de nervios propiciado pola inhumanidade de Castora e Román con Avalino, a quen convencen para que volva a aldea e así fuxir das ratas de Franco. O texto remata coa vella morta dentro do armario, que transportarán ata o piso novo.

A peza, cargada de humor e crítica social e política, está centrada en tres temas que teñen como nexo común a existencia: a relación do ser humano co espazo, o vínculo dese individuo co seu tempo e as conexións entre os distintos personaxes. En primeiro lugar, a discrepancia arredor da que xiran as demais é o cambio da casa familiar ao piso novo, é dicir, o paso do tradicional ao moderno. O personaxe da vella —e por extensión o do seu fillo Avalinodignifica o mundo rural, as súas tradicións e o dereito a vivir e morrer na súa aldea. Non obstante, xa desde a primeira referencia observamos que o moderno —o ventilador eléctrico, a afeitadora eléctrica, a aspiradora, o televisor - se funde co tradicional da casa familiar nese mesmo espazo:

[...] unha sala de casa antiga esbandallada. Por unha fiestra vense plantas e sobresae un limoeiro. Hai un lavabo de porcelana, xa verdadeira peza de museo, con palangana e espello ovalado. Unha deteriorada cama facendo xogo cun armario pequeno e unha mesa de noite. Cadeiras, maletas abertas, colgadores tirados, caixas, roupa, bonecas... Unha zaramallada á toa. En contraste, vense aparatos modernos: ventilador eléctrico, afeitadora eléctrica, aspiradora, televisor... (Graña 2009: 17-18).

No momento en que a vella morre, Román e Castora debátense entre velar o corpo na casa familiar ou facelo xa na nova vivenda. Román acouga a súa actitude e intenta que a súa muller comprenda a situación da que fora súa nai. Finalmente despídese da casa dun xeito case rosaliano:

ROMÁN: Adeus, galiñas, limoeiro, parra que daba sombra, mans que fixeron moletes, empanadas.

CASTORA: Adeus, caseto, miseria.

ROMÁN: Renovarse ou morrer... Imos subir a un décimo piso. Queremos subir á tribuna do poder...

CASTORA: Así chegarás a Director... Director de Banco... Tal vez aquí mesmo, nisto que agora aínda non é máis que un caseto. 
ROMÁN: Teñen que morrer os casetos para que nazan e medren os bancos. (Graña 2009: 62)

O conflito entre o personaxe e o espazo é un tema frecuente na dramaturxia de Bernardino Graña, por exemplo, en Larpancia saborosa do lobo e a raposa. Farsa de monifates nun lance, onde os vilegos perden a súa comida no monte e lamentan a decisión de abandonar a casa. A este respecto son reveladoras as palabras do sinfarainín: “[...] Os vilegos pouco saben deste monte. Están mellor papando a televisión... Non si? O monte han deixar tranquilo porque canten Cuco e Grilo" (Graña 2010: 35-36). Porén, tamén advertimos desemellanzas entre os vilegos en canto á súa concepción do espazo:

VILEGO $2^{\circ}$ : Do canto do cuco! Non hai mellor cousa que un cuco a cantar.

VILEGO $1^{\circ}$ : Non hai cousa mellor que un equipo a xogar... Gol!

$[\ldots]$

VILEGA 2 $2^{\text {a }}[$ [...] Gústanche os animais?

VILEGA $1^{\text {a }}$ : Gústanme... Variados... Unhas veces cocidos. Outras veces asados. VILEGA $2^{a}$ : Non. Refírome a animais vivos.

VILEGA $1^{\text {a }}$ : Ui! Vivos danme medo!

(Graña 2010: 34)

O vínculo do individuo co seu tempo en Con Franco nun armario evidénciase xa desde o propio título da peza. O tempo da historia da obra sitúase pouco despois da morte do ditador e os personaxes mencionarán unha e outra vez ese suceso: Estreliña sabe das últimas noticias pola radio; Pepe chega de Bilbao e comenta que "xa reventou o tirano" (Graña 2010: 50); Román explica que todo está de loito pola morte de Franco; Castora fálalle a Avalino da "noite longa de Franco" (Graña 2010: 50), unha noite que rexeita: "Eu non quero a noite de Franco" (Graña 2010: 50). O tratamento da temporalidade está orientada en dúas direccións, por unha banda, a mudanza ao piso novo e, por outra, o medo de Avalino. Os personaxes, principalmente Román e Castora, permanecen absortos na tarefa de recoller a casa e non se preocupan, a diferenza da súa filla, do que supón para o país a morte de Franco:

ROMÁN: E a nena, a Estreliña?

CASTORA: Aí cha anda... Outra coa cabeza tola. Agora non fai máis que darlle voltas as noticias sobre a morte de Franco.

ROMÁN: Sobre a morte de Franco?

CASTORA: $\mathrm{Si}$, que se o levan para o "val dos caídos", que se van ou non van ao seu enterramento, que se con tal vestido, con tal peiteado...

ROMÁN: Mecachis nas barbas de Barrabás! Todo parvadas [...]

(Graña 2010: 24) 
Para estes dous personaxes o acontecemento político é unha anécdota, algo secundario que só mencionan para criticar a Pepe ou para meterlle medo a Avalino. Para eles o verdadeiramente importante é rematar a mudanza canto antes:

CASTORA: (RABIOSA) Pois agoníome e con razón...

[...]

Son eu a única que quedo na casa, a mouchiña no seu souto, pero traballando, agatuñando por moitos muros. Traballando tamén coa cabeza, que debo ter clara por fóra e por dentro, para saber de toda a mandanga, de onde ha de durmir o Avalino Tobús, ter todo amañado para cando veñan os do camión, ter comida na casa, comprar as cousas que faltan... Parece que o de Franco trastornouno todo. As tendas pechan... Son moitas cousas xuntas..., moita mandanga en que pensar. (Graña 2009: 27)

En segundo lugar, a relación do individuo co seu tempo está orientado ao caso de Avalino. O seu medio irmán e a súa cuñada deciden metelo nun armario para que non lles moleste mentres rematan as súas tarefas. Román e Castora cóntanlle a Avalino que o sacarán de alí cando a noite remate. A escuridade do armario avala a mentira do matrimonio e potencia o medo do rapaz:

ROMÁN: Está negro por tódolos sitios, que morreu Franco.Todo está de luto, comprendes? Pero máis negra é a fame. Ti non tes a merendiña que che demos? Ou coméroncha os ratos?

AVALINO: Valino non quer ratos. Valino quer pombiñas.

ROMÁN: Pois conta pombiñas. As pombiñas fan fuxir os ratos. Conta moitas pombiñas. Así entreteste. E hache de vir o sono.

AVALINO: Se conto pombiñas veñen pombiñas?

ROMÁN: Veñen. Claro que veñen. Polo menos véñenche en soños. Conta pombiñas. Unha pombiña, dúas pombiñas...

AVALINO: Unha pombiña, dúas pombiñas, tres pombiñas, catro pombiñas

(Graña 2009: 38)

Román pregúntalle a Avalino se os ratos comeron a súa merenda, ao que o rapaz lle responde que non quere ratos, que quere pombas. Comeza a contar pombiñas instigado polo seu medio irmán. É interesante observar a diferenza entre a simboloxía dos ratos, relacionados coa ditadura, e a das pombas, o animal da paz por antonomasia. A vella dóese da crueldade de Román e Castora co seu fillo e pídelles que o deixen saír. Ao escoitar os lamentos da nai, Avalino comeza a bater no armario para saber que está pasando no exterior. 
As alusións á morte de Franco son continuas, do mesmo xeito que a presenza dos ratos:

AVALINO: Que hai?

$[\ldots]$

ROMÁN: Aquí non hai nada. Non pasa nada. En todo o universo non pasa nada. Segue a noite. As estrelas seguen nos seus sitios. Entendes, irmán? Morreu Franco e todo quedou ben, atado e ben atado. Todo está no seu sitio. As pombiñas no seu pombal.

[...]

ROMÁN: Pregúntasme se hai ratos?... pois...ratos sí. Ratos máis que pombas. Hai máis ratos que pombas. $\mathrm{E}$ os ratos van roer o armario no que meteron a Franco. Oes, Avalino? Os ratos van roer o armario no que meteron a Franco. AVALINO: (BATENDO) Abre! Abre, irmán!

[...]

ROMÁN: Non pode ser. Ti non tes aí a túa merendiña, a que nós che demos? AVALINO: Teño, pero non quero que me roan os ratos.

ROMÁN: Pois roe ti nela, na merenda, e ao catano (A CASTORA). Está impaciente. Haberá que...

CASTORA: Déixao estar. Déixao aí un pouco máis para que escarmente e fuxa con ganas para a aldea. Ten o autobús ben perto.

AVALINO: Valino non quer ratos.

ROMÁN: E que máis non quere Avalino?

AVALINO: Valino non quer tanta noite... Tanta... Tanta noite xunta. Ta moi neghro.

CASTORA: Está negro. Está de loito. Aquí as noites son longas... É a noite longa de Franco... E que máis non quere, Avalino? Non quere Avalino vivir na vila? (SILENCIO)

(Graña 2009: 40-43)

Ao final da obra, Castora encrequénase fronte ao corpo da vella e escúsase do acontecido dicíndolle que todo cambia e todo morre, como Franco: “[...] Tes que perdoar, vella... Sómosche así, que lle queres? [...] E aquí, ultimamente, xa non te atopabas ben. O barrio era outra aldea... Foi cambiando, morrendo, como Franco... [...] No décimo piso estaremos mellor" (Graña 2009: 64).

A tensión entre o personaxe e o seu tempo observámolo tamén no tránsito entre a tradición e a modernidade en canto á incursión de aparellos eléctricos no mundo rural. Esta variante do tema está tamén presente noutras pezas do autor, como por exemplo Sinfarainín contra don Perfeuto ou Larpancia saborosa 
do lobo e a raposa. Farsa de monifates nun lance. No primeiro dos casos o conflito principal que se presenta é o do neno Pacucho Caichovento contra o espertador don Perfeuto. A medida que avanza o texto o lector descobre que o reloxo é un agasallo que os pais de Pacucho envían desde Suíza, onde traballan recollendo cochizo ${ }^{4}$. Case ao final, un dos personaxes, o Barriga Verde, certifica esa tensión entre o tradicional e o moderno e xura en contra da televisión: "BARRIGA VERDE: — ¡A televisión! Esa sí que é unha invasión...! Si me deixaran, escagallaba un cento delas nunha noite. Máis de un cento de persoas durmirían mellor" (Graña 1975: 214). Por outra banda, en Larpancia saborosa do lobo e a raposa o roubo da comida prodúcese ao lado do Vilego $1^{\circ}$, que permanece a rentes da cesta escoitando na radio o partido de fútbol. As alusións á comodidade do fogar — cos seus respectivos aparellos modernosrepítense unha e outra vez ao longo da excursión: "VILEGOS: [...] Eu teño moito medo neste monte. Ai mamaciña! Pero se non pasa nada! O que pasa é que non debemos vir comer ao monte. Estase mellor na casa, coa televisión. Aquí hai pinchos, lagartixas, bruxas, lobos" (Graña 2010: 30); VILEGA 1ª Movéndose na televisión si... pero na casiña, quentiña... Ai, pincheime outra vez! Mecachis no monte! Xa non veño máis! Todo son pinchos e formigas e cousas raras...! [...]” (Graña 2010: 36).

O terceiro dos temas sobre os que se asenta Con Franco nun armario é o vínculo do personaxe co resto de individuos que compoñen a peza. Establecemos tres grupos a respecto do grao de implicación ante o conflito: por unha banda, a vella, que intenta loitar ata o final por non abandonar a casa familiar; no medio, Pepe, Avalino e Estreliña, o primeiro por unha simple cuestión de desinterese — porque o seu cometido único é marchar a Bilbao—, o segundo pola súa incapacidade — aínda que é certo que Avalino é feliz perseguindo o autobús da súa aldea- e a última porque só pensa en si mesma, en reclamar os seus dereitos a saír e a decidir por si propia igual que Pepe e, por outra banda, Román e Castora, que son os máis interesados en abandonar a casa familiar e establecerse no piso novo. En canto ás relacións entre personaxes, os motivos temáticos principais deste texto son a violencia, a morte e a crítica social e histórica. A violencia nesta obra aparece retratada de tres xeitos: físico, verbal e moral. Sen dúbida, a violencia física e verbal simbolizadas fundamentalmente nas disputas maritais entre Román e Castora, presentan o cariz máis afable, cargadas de sátira e humor:

4 Casca do millo ou do centeo. 


\section{ROMÁN: (TIRA UNHA TOALLA SUCIA CONTRA CASTORA) Trazas}

de podre! Barolo! Lixo!

CASTORA: Sisss! Que pasa?

ROMÁN: Que esta toalla non serve, está como unha cloaca, de sucia e mollada. CASTORA: Cloaca ti! Xa falou outra vez o machista! Valo espertar ti, animal! (Graña 2009: 35-36)

A diferenza do que observamos nas relacións entre Román e Castora consideramos que a violencia moral é, con certeza, o motivo temático máis duro que presenta a obra. A crueldade coa que tratan a Avalino é a causa da morte da vella, que é o único suceso que consegue — non sen certas vacilaciónsapouvigar as ansias de prosperidade e poder de Román e Castora.

Os motivos temáticos da violencia e da morte están presentes noutras obras teatrais de Bernardino Graña, por exemplo, en Vinte mil pesos crime. Os conflitos principais que presenta a peza son o roubo dos vinte mil pesos de Lisardo e o esclarecemento da paternidade do fillo de Nieves. Non obstante, a morte está presente desde o primeiro momento porque o texto comeza in medias res cinco meses despois do asasinato de Venancio, o namorado de Nieves. A violencia, do mesmo xeito que en Con Franco nun armario, está representada física e moralmente. Se comparamos as escenas das discusións entre Román e Castora e as de Nieves e os irmáns coa Carrexa observamos que as pretensións do autor son dotar o texto - e a posible representaciónde certo humor coa fin de atenuar o dramatismo. O compoñente satíricohumorístico está tamén presente nos finais de Os burros que comen ouro (nunca cabalos serán) e Larpancia saborosa do lobo e a raposa, que gardan certas semellanzas entre si porque rematan coa escena da muller —a Dona Gorda no primeiro exemplo e Tomasiña no segundo - coa tixola na man perseguindo o seu home para mallar nel.

O motivo temático da crítica social e histórica en Con Franco nun armario está estreitamente relacionado co tema do vínculo do individuo co seu tempo. A pretensión do autor nesta obra é a de denunciar a inhumanidade da sociedade capitalista, as ansias de poder e a ambición por ascender na escala social. A carencia de humanidade está simbolizada principalmente en Román, que decide vender a casa familiar para construír unha sucursal bancaria que pretende dirixir. No primeiro lance Castora laméntase da situación que vive, dos xogos de bebida e poder do seu marido e do traballo que desempeña a diario: 
ROMÁN: (DANDO PANCADAS A ALGUNHAS COUSAS QUE ATOPA NO CAMIÑO) Fóra! Subirei como un galo ao décimo piso! E tal vez empoleirareime na tribuna de director da sucursal... A sucursal bancaria que fagan aquí mesmo, onde está agora esta choza, este caseto... Se hai que ofrecer xamóns ofreceranse. Un banqueiro ten que vivir como un banqueiro e non en estrafalario. Hai que subir!

CASTORA: Subir... Subíronseche non sei cantas tazas de viño á moleira. Iso é o único que se che sobe...

ROMÁN: E, o entrar aquí e ver esta desorde e verte a ti con eses pelos, xa se me baixa o frautín...

CASTORA: Aínda por riba acúsasme de estar fea e de que teñamos desorde... Precisamente acúsasme ti que andas por aí de tazas e de gandallada.

ROMÁN: Se tomo tazas non é polas tazas nin pola gandallada. Ás veces teño que beber sen ganas. Teño que me levar ben cos clientes, cos compañeiros do banco, co xefe... É a política. A vida. Que sabes ti?

(Graña 2009: 22-23)

A crítica ao mundo do poder e do diñeiro son frecuentes ao longo de todo o texto, por exemplo no primeiro lance cando Castora e Román esperan a chegada de Avalino, que levará unha cabeza de porco para darlle ao director do banco. Castora denuncia a situación do pobo, gobernado precisamente por esas "cabezas de porcos” (Graña 2009: 29). A sátira social e política é un motivo temático habitual na creación dramática de Bernardino Graña, xa que aparece noutros textos como Os burros que comen ouro (nunca cabalos serán), que conta a perda dos cartos do Cacicón e a posterior dilixencia do caso. $\mathrm{O}$ feito de que o burro comera os ducados de ouro para converterse en cabalo constitúe unha crítica clara do sistema. $\mathrm{Na}$ peza constátase a confrontación dos diferentes mundos, o dos labregos e o dos políticos, e cada unha das partes dignifica a súa realidade:

SACATERRA: ¡A présa dos que andan loucos! ...

¡Capital! ¡Explotación! ...

Calemos. Gardemos algo

do moito que el roubou...

Eles rouban, mandan, falan.

Nós, calar, resignación...

Caciques, politiqueiros,

política-relumbrón.

Asombran, pasman, enganan.

Rouban e falan e falan.

Rouban con educación.

Con moito tento. Con Bancos... (Graña 1992: 25) 


\section{Conclusións}

Tras o percorrido proposto pola dramaturxia de Bernardino Graña observamos que malia estar conformada por un número reducido de títulos constitúe unha nómina homoxénea que se asenta fundamentalmente en tres elementos: a sinxeleza, o popular e a denuncia social. O teatro do autor cangués, así como toda a súa obra literaria, está dirixido de xeito unidireccional ás distintas realidades do ser humano. Para iso é fundamental destacar que a súa dramaturxia sempre alberga a confrontación de dous mundos nos que prevalece a superioridade do pobo respecto ao do poder. Os saberes e a dignidade das clases populares conviven en tensión no mundo capitalista, que impón un modo de vida cuns valores distintos aos do home do seu tempo. A natureza, concibida e contemplada como un locus amoenus, evoluciona ao tempo que o mundo e perde a súa condición de realidade ideal. Segundo o autor, a modernidade produce a deshumanización do home, que se converte nunha peza máis do crebacabezas do novo sistema. A atracción polo poder e o diñeiro son produto da substitución da actividade artesanal pola industrial onde prima a produtividade, a rendibilidade e o traballo en cadea. Para Graña, o cambio de moralidade do mundo moderno afecta as clases populares e por iso decide actuar para denunciar e dignificar os labregos, os mariñeiros e calquera persoa ou elemento relacionado coa vida do rural. A sinxeleza é unha das características principais da súa dramaturxia, non só polo tipo de personaxes retratados — que non implican falta de profundidade—, senón tamén polo rexistro de lingua utilizado, a introdución de metros populares —octosílabo, hexasílabo, pentasílabo - para a conformación de rimas, ditos e cancións ou a propia extensión dos textos xa que, agás Vinte mil pesos crime, ningunha das pezas supera os tres lances. O compoñente humorístico é outro dos trazos principais do teatro de Bernardino Graña, do que hai constancia en todas as súas obras, incluso na citada Vinte mil pesos crime, na que o humor actúa como atenuante das distintas traxedias. En canto ao tipo de público, o dramaturgo opta pola pluralidade e dirixe parte do seu teatro — como tamén da súa narrativa e poesía - ao lectorado infantil e xuvenil, aos que considera a personificación da ilusión, o entusiasmo e a curiosidade. $\mathrm{O}$ autor escribe desde o neno que el é porque entende que a revolución está no infantil, así como afirmou nunha entrevista publicada en Aula infima (Graña 1994: IVIII). Ademais recoñece a importancia da literatura de tradición oral para a formación dos futuros lectores e, por iso, toma elementos da fala como punto de partida para a creación dos seus textos. 
No caso concreto de Con Franco nun armario, o autor diríxese á mocidade para presentarlles unha nova visión da transición da ditadura á democracia, así como da noite que supuxo para el e para a súa xeración a época franquista. Porén, o texto non se limita exclusivamente ao plano político senón que tamén denuncia o tránsito da tradición á modernidade a partir de tres temas que xiran arredor da existencia humana, os seus espazos, o seu tempo e as súas relacións cos outros. Os contextos de violencia física e moral constrúen unha peza teatral que se debate entre a sátira humorística e a traxedia para concluír coa vitoria dos antagonistas. A publicación desta obra — e a da farsa posterior de 2010 — supuxo a consolidación de Bernardino Graña como dramaturgo para a infancia e mocidade. Deste xeito, cumpriu case dúas décadas despois a súa promesa de volver a visitar o teatro, ese amigo que, malia o paso dos anos, continuaba vivindo dentro del.

Laura Piñeiro Pais Centro Ramón Piñeiro para a Investigación en Humanidades

\section{Referencias bibliográficas}

Agrelo Costas, Eulalia. 2015. "V.1. Contexto e factores sistémicos". En Historia da Literatura Infantil e Xuvenil Galega (coord. Blanca-Ana Roig Rechou). Vigo: Edicións Xerais de Galicia, pp. 283-205.

Carballo Calero, Ricardo. 1962. "Bocaccio en Galicia", en Faro de Vigo, 29 xullo 1962.

Carré Alvarellos, Leandro. 1931. "Apontamentos para a historia do teatro galego", en Boletín da Real Academia Galega, 235-240, pp. 213-224.

Fernández Lorenzo, Rafael e Héitor Mera Herbello (eds.). 2005. Conversas con Bernardino Graña. Vigo: Edicións Xerais de Galicia.

Fontoira Surís, Ma Lydia. 1973. "O teatro en 'Illa Nova”, en Grial, 41, pp. 360-369.

Graña, Bernardino. 1975. "Sinfarainín contra Don Perfeuto", en Grial, 48, pp. 201-217.

Graña, Bernardino. 1992. Os burros que comen ouro (nunca cabalos serán). [Barcelona]: Sotelo Blanco Edicións. 
Graña, Bernardino. 1994. "Bernardino Graña: Entrevista”, en Aula ínfima. Revista dos estudantes da Faculdade de Xeografía e Historia, 4, marzo 1994, pp. I-VIII.

Graña, Bernardino. 2005. Vinte mil pesos crime (ed. Héitor Mera). Vigo: Edicións Xerais de Galicia.

Graña, Bernardino. 2009. Con Franco nun armario. Vigo: Edicións A Nosa Terra.

Graña, Bernardino. 2010. Larpancia saborosa do lobo e a raposa. Ferrol: Edicións Embora.

Mera Herbello, Héitor. 2005. "Introdución”. En Bernardino Graña. Vinte mil pesos crime (ed. Héitor Mera). Vigo: Edicións Xerais de Galicia, pp. 8-56.

Riobó Sanluís, Pedro Pablo. 1999. O teatro galego contemporáneo (1936-1996). A Coruña: Universidade da Coruña. Col. Biblioteca-Arquivo Teatral "Francisco Pillado Mayor". Serie Azul, 9. 